\title{
Uncertainty-Compensating Neural Network Control for Nonlinear Systems
}

\author{
Hyun-Seob Cho ${ }^{1^{*}}$ \\ ${ }^{1}$ Dept. of Digital Broadcasting \& Electronic Engineering, Chungwoon Univ., \\ 비선형 시스템의 불확실성을 보상하는 신경회로망 제어 \\ 조현섭 $^{1^{*}}$ \\ ${ }^{1}$ 청운대학교 디지털방송공학과
}

\begin{abstract}
In this paper, a direct controller for nonlinear plants using a neural network is presented. The composed of the control input by using RBF neural networks and auxiliary input to compensate for effects of the approximation errors and disturbances. In the results, using this scheme, the output tracking error between the plant and the reference model can asymptotically converge to zero in the presence of bounded disturbances and approximation errors. Simulation results show that it is very effective and can realize a satisfactory control of the nonlinear system.

요 약 본 논문은 비선형 동적 신경망을 이용하여 직접 제어에 관한 연구이다. RBF 신경망을 이용한 제어입력과 근사화 오차 및 외란의 영향을 제거하기 위한 보조제어 입력으로 구성하였다. 외란이나 근사화 오차에 관계없이 플 랜트와 기준모델 사이의 오차가 0이 되도록 하는 알고리즘을 구할 수 있었다. 시뮬레이션 결과는 매우 효과적이며 비선형 시스템의 만족스러운 학습 성능을 증명하였다.
\end{abstract}

Key Words : Nonlinear systems, Robustness Control, Plants of Auto-equipment Systems, Dynamic Neural Processor, Robustness Control

\section{Introduction}

The conventional design methods of a control system often require the construction of a mathematical model describing the dynamic behavior of the plant to be controlled. When such a mathematical model is difficult to obtain due to uncertainty or complexity of systems, these conventional techniques based on a mathematical model are not well suited for dealing with. Artifical neural network teachiques have been suggested for identification and control of nonlinear plants for which conventional techniques of control do not give satisfactory performance, such as the accuracy in matching the behavior of the physical system. A good method of applying neural networks for control must have the following properties:

1. It must be applicable to nonlinear plants, since there are already good methods of control for linear plants.

2. It should not put too much restriction on the type of non linearity that it can handle.

3. It is preferable to have an Unsupervised Learning method for the neural network because the desired output form of a system for a given input may be known, but the input form of a plant that produces that desired output is not generally known. Unsupervised Training can avoid identification of the plant or its inverse model, which is generally not easy to obtain.

4. The system should be stable at least for the class of inputs it has been trained for.

5. In most cases open loop performance of a plant can

*Corresponding Author : Hyun-Seob Cho(chohs@chungwoon.ac.kr)

Received December 31, 2009 Revised February 26, $2010 \quad$ Accepted May 13, 2010 
be observed and a approximate controller can be devised for that. It would be desirable if we could put as much knowledge as possible in the design of this controller and only leave the extra fine tuning to the neural network controller. According to the above requirements, a direct auxiliary controller for nonlinear plants using neural network is presented.

\section{Controller Design}

The controller presented here is composed of an approximate controller and a neural network auxiliary controller. The structure of controller is shown in Figure 1. The approximate controller gives the approximate performance and the neural network auxiliary controller is used for the purpose of further fine tuning.

The approximate controller can be a PID or any other conventional controller. It can be designed by using the known dynamics of nonlinear plant. The neural network employed in this scheme is an Radial Basis Function Network (RBF). It produces the complementary signal to further reduce the error $\mathbf{e}$ between output $\mathbf{y}$ and the reference input $\mathbf{r}$. The structure of RBF is showed in Figure 2. It is a network with two layers. A hidden layer of radial basis neurons and an an output layer of linear neurons. A common choice for the basis function is a Gaussion given by the equation:

$$
G_{i}(x)=\exp \left(-\frac{\left\|x-c_{i}\right\|^{2}}{2 \sigma^{2}}\right), i=1,2, \ldots m
$$

Where $\mathrm{Ci}$ represents the center of the basis function and denotes its width. The norm \|\| in equation can be expressed by Euclidean distance. The weights and biases of each neuron in the hidden layer define the position and width of a radial basis function. Each linear output neuron forms a weighted sum of these radial basis functions. With the correct weight and bias values for each layer, and enough hidden neurons, a RBF can fit any function with any desired accuracy. The advantage of the RBF is its rapid learning, generality and simplicity. RBF finds the input to output map using local approximators. It can be trained faster than BP and have none of BP's training problems such as saturation and local minima.

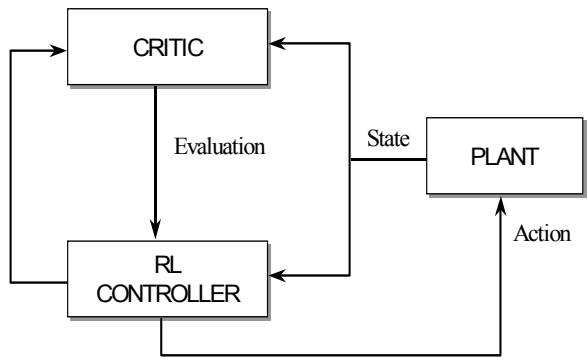

[Fig. 1] The structure of the controller

In the RBF training stage we first observe the performance of the system with the approximate controller for a certain period of time and measure the range of error between the output of the plant and desired output. Then we divide this error span into certain sections and for each section we perform a perturbation test: We increased the input to the plant by $\mathrm{e}$ whenever total square error between the output of the plant and desired output falls within a specified region. If this change of the input results in a lower value of the total square error, we modify the output weight of the neural network controller to work accordingly. This action is continued for all sections and the whole process is repeated until no modification can reduce the error.

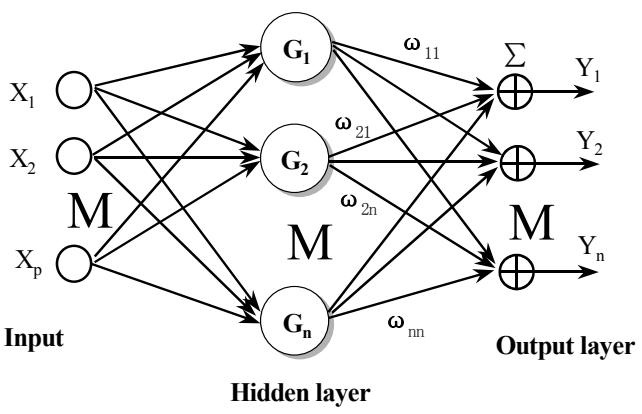

[Fig. 2] Radial Basis Function Network

Taking an overlapping Gaussian activation function for kernel units supposedly provides a smoother response and better generalization. but in our case the amount of interference was so high and we obtained a better performance with non-overlapping regions. Nevertheless, smoothness of the output can be enhanced by dividing the 
correction for each section by modifying the cost function used for training from $\mathrm{J}=$ ?e 2 to $\mathrm{J}=$ ?(enew $2+\mathrm{k}$ (enew -eold)2) for $\mathrm{k}<1$.

During the training stage, each time only one kernel unit responds and one weight is adjusted, This results in a shorter training time compared with Multi-layer Perceptron (MLP) type networks. Since weights are adjusted by a small value each time, the number of necessary iterations depends on the size of error or the accuracy of the approximate controller.

The point that makes this method different is the way in obtaining the necessary corrections, which is based on the effect of weight perturbation on the total square error for a certain period of time. Perturbing the weights of a network is used in Madaline Rule III (MR III) training for analog implementation of neural networks. Because this method does not need prior knowledge about the transfer characteristics of the computing devices, it is not affected by the effects of neuron to neuron variations. Training the network based on its instantaneous result of the error will cause instability when used in a feedback loop. The performance of the system here is observed for a certain period of time and if any adjustment for any given amount of error increases the total square error, it would not be accepted. This proves the stability of the system for the class of inputs it has been trained for.

Generally optimization methods based on parameter perturbation are bound to failure when many parameters are involved in perturbation and that is because of the moving target effect of the other parameters. It is not the case in the proposed system for which only one or few related parameters are active at each time. At present, methods for directly adjusting the control parameters based on the output error are not available. The work presented in this paper is a step toward direct adaptive control.

\section{Simulation Study}

Differ net nonlinear systems were considered to evaluate the effect of the proposed method. Figure 3 gives the effect of controller when it is used for three different nonlinear plants. In this figure, $\mathrm{y}($.$) denotes the$ plant output without controller, ym(.) denotes the desired output, $\mathrm{r}($.$) denotes the reference input and yc(.) denotes$ the output of the plant with controller. An RBF type network with 30 kernel units each sensitive to different ranges of error was used. Input weights and activation function of the units were fixed. Output weights were perturbed and adjusted according to the effect of perturbation on the total square error for 400 sampling time. For a sinusoidal input $(\mathrm{r}(\mathrm{k})=\sin (\mathrm{k} / 50))$ and perturbation amount of $=0.1$, the amount of reduction in aggregated square error for a full cycle of input is example 1:from 3.69 to 1.33 , expmple 2:from 105.84 to 26.44 and example 3 :from 32.11 to 4.56 . To observe the learning and generalization capability of the system, the controller was trained on a step response and its performance was observed on the sinusoidal input. Training the network with different types of input will enchance the generalization capability of the system.

Example 1

$$
\left\{\begin{array}{l}
y(k)=\frac{1.2 y(k-1)}{1+y(k-1)^{2}}+0.5 u(k-1) \\
y_{m}(k)=0.3 y_{m}(k-1)+0.2 y_{m}(k-2)+0.5 r(k-1)
\end{array}\right.
$$

Example 2

$$
\left\{\begin{array}{c}
y(k)=\frac{y(k-1) y(k-2)(y(k-1)+2.5)}{1.3+y(k-1)^{2}+y(k-2)^{2}}+1.5 u(k-1) \\
y_{m}(k)=0.7 y_{m}(k-1)+0.1 y_{m}(k-2)+r(k-1)
\end{array}\right.
$$

Example 3

$$
\begin{gathered}
\left\{\begin{array}{c}
y(k)=\operatorname{sat}(0.5 y(k-1)+0.2 y(k-2)+2.1 u(k-1)) \\
y_{m}(k)=0.48 y_{m}(k-1)+0.2 y_{m}(k-2)+r(k-1)
\end{array}\right. \\
\left(\operatorname{sat}(x) \equiv-3+\frac{6}{1+\exp (-x)}\right)
\end{gathered}
$$

\section{Conclusions}

A neural network controller for nonlinear plants is used in combination with an existing conventional controller, which removes the need for a generalized training scheme. The controller is guaranteed to perform stably for the class of inputs that it has been trained for. Using this method of control does not require assumption of a model for the plant and it makes it different from conventional control methodologies.

Furthermore, since training of this network does not require backpropagation of error, it makes direct adaptive 
control possible, a structure beyond the capabilities of backpropagation based on neural networks. The structure used here can be view as a fuzzy controller implementation for which the control actions or rules which depend on the error between the plant output and the desired output are deduced in training time.It can also be viewed as a gain scheduling adaptive controller which can work for any unknown plant with no attempt to linearize the system at each region.

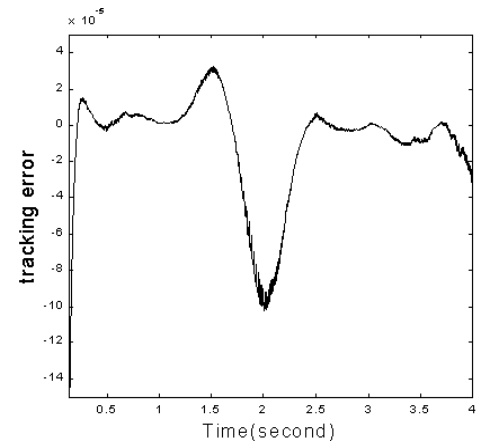

(a) Example1

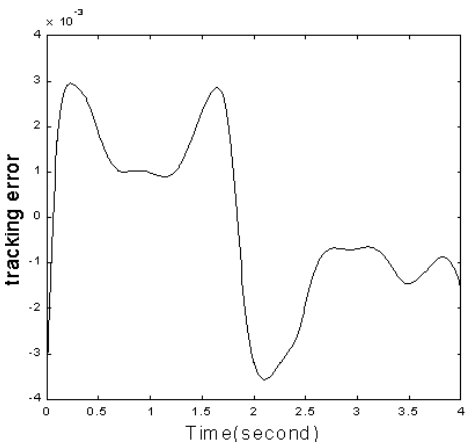

(b) Example2

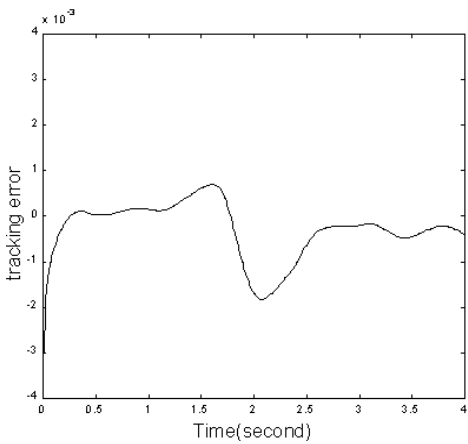

(c) Example3

[Fig. 3] $\mathrm{Ym}($.$) is the output of the reference model, \mathrm{Y}($. is the output of system without NNC and $\mathrm{Yc}($. is the output of system without $\mathrm{NNC}$ in the example1,2 and 3 .

\section{참고문헌}

[1] G.A.Montague,M.J.Willis and A.J.Morris, "Artificial Neural Network Model Based Control"Automatic Control Conference, 1998

[2] M.M.Gupta and D.H.Rao,"Dynamic Neural Units in the Control of Linear and Nonlinear Systems."In Proceedings of the International Joint Conf. On Neural Networks,June 2005,pp.100-105

[3] D.Andes,B.Widrow,M.Lehr and E.Wan,"MR III:A Robust Algorithm for Training Analog Neural Networks" International Joint Conference on Neural Networks, 2000

[4] K.S.Narendra and K.Parthasarathy, "Identification and Control of Dynamical Systems Using Neural Networks" IEEE Trans on Neural Network Vol.1 No.1,pp.4-27,2002

[5] J. Moody and C.J.Darken, "Fast learning in Networks of Locally-Tuned Processing Units" Neural Computation, Vol.1, pp.281-194, 2005.

[6] Howard Demuth,Mark Beale,"Neural Network ToolBox for Use with MATLAB"The MathWorks Inc., 2008

[7] Chen S,Billing S A,"Grant P M.Recursive Hybrid Algorithm for Nonlinear System Identification using Radial Function Network", Int.JControl,1992,55(5): 105-1070

\section{Hyun-Seob Cho}

[Life member]

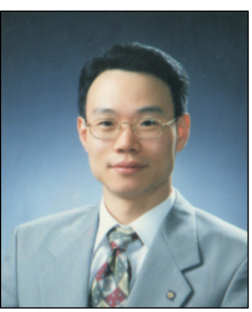

- Feb. 1990 : Wonkwang University The department of Electrical Engineering

- Feb. 1992 : Wonkwang University The M.E.course of the Department of Electrical Engineering

- Feb. 1996 : Wonkwang University Graduate School The Ph.D.course of the Department of Electrical Engineering

- Mar. $1997 \sim$ current : Chungwoon University Professor. Department of Electronic Engineering.

$<$ Research Interests $>$

Electric and Electronics Application, Automatic Control 